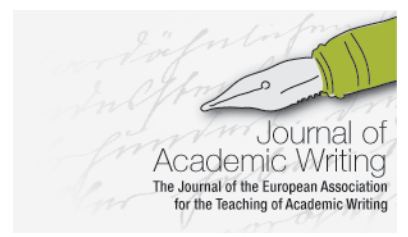

Journal of Academic Writing

Vol. 1 No 1 Autumn 2011, 12

\title{
Student Writing in Transition: Crossing the Threshold?
}

\author{
Mary Scott \\ Institute of Education, England
}

\section{Introduction}

The following set of three papers, 'University Literacies: French Students at a Disciplinary "Threshold"?' by Isabelle Delcambre and Christiane Donahue, 'Modeling Multivocality in a U.S.Mexican Collaboration in Writing across the Curriculum', by Mya Poe and Jennifer Craig, and 'Perceptions and Anticipation of Academic Literacy: "Finding Your Own Voice"', by Claire Woods and Paul Skrebels, represents some of the ongoing practice-oriented research of the 'Antwerp Group', so called because the members came together as teacher-researchers with shared interests in student writing in Antwerp in 2006. The purpose of the group is to explore and compare student writing across different stages of higher education and to highlight issues and complexities that international studies tend to ignore in a preoccupation with statistical findings. To date the group comprises individuals in six countries: the US, the UK, the Netherlands, France, Qatar and Australia.

In their papers members of the group offer their most recent research for comment and critique. They explore sites of transition, cultural diversity and liminality (in-betweeness) in order to problematize current approaches to students' writing at those points in higher education where students are confronted by the need to cross a new threshold (limen) as institutionally defined. In keeping with this orientation to the theoretical and empirical, the papers focus on different moments/stages of transition: school to university; first year to final year; undergraduate to postgraduate. They briefly present the studies that they have been individually engaged in in four countries: Australia, France, the UK, and the US, and they show how the studies are bringing to light students' in-betweenness as the students engage with academic discourses in all their complexity. In view of that complexity the papers jointly propose the following question: How appropriate/useful is 'crossing the threshold' as a metaphor to describe student writing in transition? They suggest that it is a particularly important question in view of the increasing mobility of students across countries, disciplinary areas, and modules. 